\title{
A Molecular Survey of Hypoxanthine-Guanine Phosphoribosyltransferase Deficiency in Man
}

James M. Wilson, J. Timothy Stout, Thomas D. Palella, Beverly L. Davidson, William N. Kelley, and C. Thomas Caskey

Departments of Internal Medicine and Biological Chemistry, University of Michigan, Ann Arbor, Michigan 48109, and Departments of Medicine, Biochemistry, and Cell Biology, Baylor College of Medicine and Howard Hughes Medical Institute, Houston, Texas 77030

\begin{abstract}
We characterized 24 unrelated patients with a deficiency of the enzyme hypoxanthine-guanine phosphoribosyltransferase (HPRT) in an attempt to better understand the nature and spectrum of mutations that underlie this prototype-inherited disease. Lymphoblast cell lines derived from each patient were analyzed at multiple molecular levels including the structure and function of the residual HPRT enzyme, messenger RNA (mRNA), and gene. Our studies demonstrate the following: $(a)$ at least 16 of the 24 patients represent unique and independent mutations at the HPRT structural gene; $(b)$ the majority of cell lines have normal quantities of mRNA but undetectable quantities of enzyme; (c) 33\% of patients retain significant quantities of structurally altered, functionally abnormal, HPRT enzyme variants; and $(d)$ a minority of patients are void of both enzyme and mRNA, possibly representing examples of aberrations in gene expression. Our studies provide direct evidence for marked genetic heterogeneity in this disorder and illustrate the kinds of mutations and mutational consequences that underlie inherited disease in humans.
\end{abstract}

\section{Introduction}

Hypoxanthine-guanine phosphoribosyltransferase (HPRT) ${ }^{1}$ deficiency is an inherited disorder of purine metabolism that has wide-ranging phenotypic effects. A virtual absence of HPRT activity is found in patients with the Lesch-Nyhan syndrome (1). This X-linked recessive disease is characterized by an overproduction of uric acid as well as the development of uric acid nephrolithiasis, choreoathetoid movements, spasticity and hyperreflexia, severe mental and growth retardation, and a bizarre pattern of patients' self-mutilation characterized by compulsive biting of their fingers and lips (2).

Patients with a partial deficiency of enzyme activity are spared the devastating neurological and behavioral abnormalities that characterize the Lesch-Nyhan syndrome. This latter group of patients usually presents with a severe form of gouty arthritis or uric acid nephrolithiasis in early adulthood (3).

Dr. Wilson's current address is Medical Services, Massachusetts General Hospital, Boston, MA 02114.

Received for publication 25 July 1985

1. Abbreviations used in this paper: $\mathrm{CRM}^{+}$, enzyme positive; HPRT, hypoxanthine-guanine phosphoribosyltransferase; PRPP, 5-phosphoribosyl-1-pyrophosphate; RFLP, restriction fragment length polymorphism.

J. Clin. Invest.

(C) The American Society for Clinical Investigation, Inc.

0021-9738/86/01/0188/08 $\$ 1.00$

Volume 77, January 1986, 188-195
HPRT deficiency has recently emerged as a prototype for defining the nature and functional consequences of clinically deleterious mutational events and for designing novel therapeutic modalities that attempt to modulate gene expression. Several aspects of this inherited disorder make it particularly amenable to detailed molecular analyses. Our knowledge of normal HPRT protein $(4,5)$, mRNA $(6,7)$, and gene $(8,9)$ provides a basis for the precise delineation of the abnormalities present in enzymedeficient patients. The isolation of mutant genes and their products is simplified because the affected male patients are hemizygous for the HPRT locus $(1,3)$, and the gene is expressed in a wide variety of human tissues, including cultured cells (10). We documented in an earlier report the utility and validity of using viral transformed lymphoblasts in tissue culture as a source for the isolation of mutant HPRT gene products (11).

A variety of mutations have now been described in HPRTdeficient patients. Single unique amino acid substitutions have been identified in four dysfunctional enzyme variants; three mutant enzymes were isolated from gouty patients (12-14) and one was isolated from a Lesch-Nyhan patient (15). Yang et al. (16) screened a series of Lesch-Nyhan patients for major rearrangements in the HPRT gene and identified unique abnormalities in five unrelated patients. These important preliminary investigations have provoked several more fundamental questions.

A complete deficiency of HPRT activity is not lethal in utero, but does lead to nonreproductive affected males (17). Given the genetic lethal characteristics of the disease, what is the diversity and prevalence of new mutations in Lesch-Nyhan syndrome? Furthermore, is there a correlation between types of mutations or mutational consequences and clinical phenotype? Finally, what is/are the molecular defect(s) in the many Lesch-Nyhan patients who have grossly normal structural genes but lack enzyme protein?

In an attempt to answer these important questions we have undertaken a comprehensive analysis of the molecular basis of HPRT deficiency in a large group of patients. Lymphoblastoid cell lines were established from 24 unrelated enzyme-deficient patients representing both clinical syndromes. These cell lines were characterized at multiple molecular levels including (a) HPRT enzyme concentration, function, and structure, $(b)$ HPRT mRNA concentration and molecular size, and $(c)$ gross structure of the HPRT gene.

\section{Methods}

Subjects and cell lines. HPRT-deficient patients were divided into two clinical subgroups: those who presented with the Lesch-Nyhan syndrome and those who presented with gouty arthritis and/or uric acid nephrolithiasis. Criteria used in establishing a diagnosis of Lesch-Nyhan syndrome include: (a) virtual absence of HPRT activity in erythrocytes, $(b)$ growth and mental retardation, $(c)$ evidence for pyramidal and/or extrapyramidal tract dysfunction, and $(d)$ compulsion to self-inflict painful 
wounds usually manifested by self-mutilation of the hands and lips. The second clinical subgroup represents a heterogeneous population of patients who $(a)$ present with gouty arthritis and/or uric acid nephrolithiasis at an early age, $(b)$ demonstrate a broad spectrum of HPRT activity in erythrocytes (from undetectable to $\sim 50 \%$ of activity), (c) usually have completely normal neurological function, but may have mild to moderate neurological abnormalities (e.g., learning disabilities or hyperreflexia), and $(d)$ never manifest the compulsive self-destructive behavior that is characteristic of the Lesch-Nyhan syndrome.

Lymphoblastoid cell lines were established for each patient by EpsteinBarr virus-mediated transformation of peripheral blood B lymphocytes. Methods used in the establishment and maintenance of lymphoblastoid cell lines have been described (11). Cell lines GM2292, GM1899, and GM6804 were obtained from The Human Mutant Cell Repository, Camden, NJ.

Enzyme assays. Membrane-free protein extracts were prepared from freshly harvested lymphoblast cultures as described (11). Sensitive radiochemical and immunochemical techniques were used to quantify HPRT enzyme activity (18) and immunoreactive protein (19), respectively.

Measurements of apparent Michaelis constants $\left(K_{\mathrm{m}}\right)$ for hypoxanthine ( $K_{m}$-hypoxanthine) and 5-phosphoribosyl-1-pyrophosphate ( $K_{\mathrm{m}}$-PRPP) were performed in the presence of near saturating concentrations of the other substrate for all enzymes except $\mathrm{HPRT}_{\text {Kinston }}$ and $\mathrm{HPRT}_{\text {Munich. }}$. It was impossible to measure the $\mathrm{K}_{m}-\mathrm{PRPP}$ of $\mathrm{HPRT}_{\text {Kinston }}$ and $\mathrm{HPRT}_{\text {Munich }}$ in the presence of saturating concentrations of hypoxanthine due to each enzyme's elevated $\mathrm{K}_{m}$-hypoxanthine and the limited solubility of hypoxanthine in aqueous solution. The following experimental conditions were used for all enzymes except HPRT $\mathrm{T}_{\text {Kinston }}$ : apparent $\mathrm{K}_{m}$ for hypoxanthine, varying hypoxanthine $(300-3 \mu \mathrm{M})$ in the presence of $6 \mathrm{mM}$ $\mathrm{MgCl}_{2}$ and $1 \mathrm{mM}$ PRPP; apparent $K_{\mathrm{m}}$ for PRPP, varying PRPP (1-0.01 $\mathrm{mM}$ ) and $\mathrm{MgCl}_{2}$ (kept in excess of PRPP by $5 \mathrm{mM}$ ) in the presence of $300 \mu \mathrm{M}$ hypoxanthine. The following conditions were used in the analysis of HPRT $\mathrm{K}_{\text {Kinston }}$ : apparent $\mathrm{K}_{m}$ for hypoxanthine, varying hypoxanthine (300-3 $\mu \mathrm{M})$ in the presence of $20 \mathrm{mM} \mathrm{MgCl} 2$ and $10 \mathrm{mM}$ PRPP; and apparent $K_{\mathrm{m}}$ PRPP, varying PRPP (2.5-0.025 mM) and $\mathrm{MgCl}_{2}$ (kept in excess of PRPP by $5 \mathrm{mM}$ ) in the presence of $300 \mu \mathrm{M}$ hypoxanthine.

Maximal velocities were calculated from measurements of enzyme activity and immunoreactive protein in membrane-free extracts. The maximal velocity is defined as the initial rate (milliunits per milligram protein), measured in the presence of saturating concentrations of hypoxanthine and PRPP, divided by the level of HPRT immunoreactive protein (nanograms CRM per milligram protein). However, maximal velocities for HPRT Kinston $_{\text {and }}$ HPRT Munich $_{\text {were extrapolated from assays }}$ performed in the presence of subsaturating concentrations of hypoxanthine.

Protein blot analysis. Protein extracts were subjected to polyacrylamide gel electrophoresis in the presence or absence of sodium dodecyl sulfate (SDS) as described previously. Electrophoretic transfer of proteins from nondenaturing gels to nitrocellulose paper has been well described (11). Proteins were transferred from SDS gels to nitrocellulose paper as described by Towbin et al. (20) except that the transfer was carried out for $3 \mathrm{~h}$ at $50 \mathrm{~V}$. Detection of HPRT in situ, after transfer from either nondenaturing or SDS gels, was effected immunochemically using previously published methods (11).

Analysis of radiolabeled HPRT proteins. Lymphoblasts from a normal male subject and from patient D.B. were labeled in culture with $\left[{ }^{35}\right.$ S $]$ methionine. ${ }^{35} \mathrm{~S}$-labeled HPRT protein was purified to radiochemical homogeneity by immunoprecipitation with a highly specific antibody. Immunoprecipitates were analyzed by SDS-polyacrylamide gel electrophoresis. The labeling, purification, and electrophoretic analysis of $\left.{ }^{35} \mathrm{~S}\right] \mathrm{HPRT}$ has been described (11).

RNA isolation and Northern blot analysis. Total RNA was isolated in the presence of guanidine- $\mathrm{HCl}$ as described (21). $50 \mu \mathrm{g}$ of RNA was electrophoresed in a $0.8 \%$ agarose gel, transferred to nitrocellulose, and hybridized with ${ }^{32} \mathrm{P}$-deoxycytidine triphosphate (dCTP) nick-translated HPRT cDNA (21).

DNA isolation and Southern blot analysis. High-molecular-weight
Table I. HPRT Activity and Immunoreactive Protein in Enzyme-Deficient Lymphoblasts

\begin{tabular}{|c|c|c|c|c|}
\hline \multirow[t]{2}{*}{$\begin{array}{l}\text { Patients or } \\
\text { cell lines }\end{array}$} & \multicolumn{2}{|l|}{ Specific activity } & \multicolumn{2}{|c|}{ Immunoreactive protein } \\
\hline & $m U / m g$ & \% control & $n g C R M / m g$ & \% control \\
\hline Controls & $14.5 \pm 3.6(3)^{*}$ & 100 & $332 \pm 96(3)^{*}$ & 100 \\
\hline \multicolumn{5}{|l|}{ Lesch-Nyhan } \\
\hline D.A. & $<0.1(2) \ddagger$ & $<0.7$ & $<1.5(2)$ & $<0.5$ \\
\hline A.C. & $<0.1(2)$ & $<0.7$ & $<1.5(3)$ & $<0.5$ \\
\hline E.C. & $<0.1(2)$ & $<0.7$ & $<1.5(2)$ & $<0.5$ \\
\hline H.D. & $<0.1(4)$ & $<0.7$ & $<1.5(2)$ & $<0.5$ \\
\hline W.E. & $<0.1(2)$ & $<0.7$ & $<1.5(2)$ & $<0.5$ \\
\hline D.G. & $<0.1(2)$ & $<0.7$ & $167 \pm 38(7) \S$ & 50 \\
\hline J.H. & $<0.1(2)$ & $<0.7$ & $<1.5(2)$ & $<0.5$ \\
\hline D.M. & $<0.1(2)$ & $<0.7$ & $<1.5(3)$ & $<0.5$ \\
\hline HPRT $_{\text {Kinston }} \|$ & $<0.1(2)$ & $<0.7$ & $240 \pm 29(6)$ & 72 \\
\hline B.S. & $<0.1(2)$ & $<0.7$ & $<1.5(3)$ & $<0.5$ \\
\hline K.T. & $<0.1(4)$ & $<0.7$ & $304 \pm 50(8)$ & 92 \\
\hline GM2292 & $<0.1(2)$ & $<0.7$ & $<1.5(2)$ & $<0.5$ \\
\hline GM1899 & $<0.1(2)$ & $<0.7$ & $5.4,3.6$ & 1.3 \\
\hline GM6804 & $<0.1(2)$ & $<0.7$ & $<1.5(2)$ & $<0.5$ \\
\hline McA & $<0.1(2)$ & $<0.7$ & $<1.5(2)$ & $<0.5$ \\
\hline \multicolumn{5}{|l|}{ Gout } \\
\hline D.B. & $10.0 \pm 2.2(5)$ & 69 & 172 & 52 \\
\hline P.C. & $<0.1(4)$ & $<0.7$ & $15.2,12.0$ & 4 \\
\hline HPRT $_{\text {Ann Artor }}$ & $1.5 \pm 0.2(4)$ & 10 & $37 \pm 3(6)$ & 11 \\
\hline B.D. & $<0.1(4)$ & $<0.7$ & $5.1,6.7$ & 2 \\
\hline J.M. & $0.2 \pm 0.1(6)$ & 1.4 & $10.8,10.0$ & 3 \\
\hline HPRT $_{\text {Toronto" }}$ & $4.8 \pm 0.3(4)$ & 33 & $172 \pm 20(6)$ & 52 \\
\hline HPRT $_{\text {London }}$ & $8.6 \pm 0.6(6)$ & 59 & $116 \pm 11(7)$ & 35 \\
\hline R.T. & $<0.1(6)$ & $<0.7$ & $2.9,2.7$ & 0.8 \\
\hline HPRT $_{\text {Munich" }}$ & $0.4 \pm 0.1(6)$ & 3 & $263 \pm 17(6)$ & 79 \\
\hline
\end{tabular}

* Mean \pm 1 SD for three control lymphoblast cell lines, taken from reference 11. $¥$ Mean; $(n)=$ number of determinations.

$\S$ Mean $\pm 1 \mathrm{SD} ;(n)=$ number of determinations.

"Obtained from reference 11 .

DNA was isolated from cultured lymphoblasts as described (21). DNA was digested to completion with one of several restriction endonucleases under conditions recommended by the manufacturer (Bethesda Research Laboratories, Gaithersburg, MD, and New England Biolabs, Beverly, MA). Restricted DNA was fractionated in $0.8 \%$ agarose gels, transferred to nitrocellulose paper, and probed with ${ }^{32} \mathrm{P}$-labeled DNA as described (16).

\section{Results}

HPRT enzyme activity and immunoreactive protein. Lymphoblast cell lines were established from 24 unrelated HPRT-deficient patients. 15 patients presented with the Lesch-Nyhan syndrome and 9 patients presented with gout and/or nephrolithiasis. Previous studies have demonstrated unique mutant forms of HPRT in five of these patients $(11-15,19){ }^{2}$ These variants have been named HPRT Kinston $_{1}, \mathrm{HPRT}_{\text {Ann Arbor }}, \mathrm{HPRT}_{\text {Toronto }}$, HPRT $_{\text {London }}$, and HPRT Munich. $_{\text {. }}$

Levels of HPRT enzyme activity and immunoreactive protein are summarized in Table I. Activity assays were carried out in the presence of hypoxanthine and PRPP concentrations that exceed the normal Michaelis constants by 60 -fold and 120 -fold, respectively. HPRT enzyme activity was undetectable $(<0.7 \%$ of control) in all Lesch-Nyhan patients, while HPRT immu-

2. Two patients described by Yang et al. (16) were also included in our study; lymphoblast cell lines McA and GM 6804 correspond to Yang et al.'s fibroblast cell lines RJK 853 and GM1662, respectively. 
noreactive protein was undetectable $(<0.5 \%$ of control) in 11 of 15 Lesch-Nyhan patients; a low level of enzyme protein was measured in cell line GM1899 (1\% of control) while substantially higher levels were measured in patients D.G. (50\% of control), HPRT $_{\text {Kinston }}(72 \%$ of control), and K.T. ( $92 \%$ of control). Patients who presented with gout exhibited a broad range of activity from undetectable (patients R.T., P.C., and B.D.) to $69 \%$ of control (patient D.B.). HPRT immunoreactive protein was detected in each patient with gout; however, the range of enzyme concentration was wide (from 0.8 to $79 \%$ of control).

Kinetic properties of enzyme variants. Cultured lymphoblasts with $>10 \%$ residual HPRT protein were further characterized with respect to the kinetic properties of the residual HPRT protein. Included in this group were cell lines expressing the five known HPRT variants and three previously undescribed cell lines, D.B., D.G., and K.T. Table II summarizes the measured Michaelis constants for hypoxanthine and PRPP, and the calculated maximal velocity of each variant. Significant kinetic abnormalities were detected in all variants except HPRT $_{\text {Toronto }}$. These data confirm earlier kinetic analyses of $\mathrm{HPRT}_{\text {Kinston }}(22)$, HPRT $_{\text {Munich (23), HPRT }}$ Toronto (24), and enzyme from D.B. (25), isolated from either erythrocytes or fibroblasts. HPRT from patient D.B. was indistinguishable from HPRT London $_{\text {in terms of }}$ kinetic dysfunction; both enzymes exhibited a slight increase in $V_{\max }$ and a sixfold increase in $K_{\mathrm{m}}$-hypoxanthine. Enzyme activity was undetectable in extracts from D.G. and K.T., precluding kinetic analysis of the mutant enzymes.

Electrophoretic analysis of enzyme variants. The previously undescribed enzyme-positive patients were further characterized with respect to the electrophoretic properties of the residual HPRT protein. Membrane-free extracts were subjected to polyacrylamide gel electrophoresis, in the presence or absence of SDS, and HPRT enzymes were detected immunochemically using the protein blot technique.

Table II. Kinetic Properties of HPRT Variants

\begin{tabular}{llll}
\hline & \multicolumn{2}{l}{ Michaelis constants } & \\
\cline { 2 - 4 } Mutant & Hypoxanthine & PRPP & $\begin{array}{l}\text { Maximal } \\
\text { velocity* }\end{array}$ \\
\hline & $\mu M$ & $\mu M$ & $m U / \mu g C R M$ \\
Controls & $3.5 \pm 2.4(3) \ddagger$ & $16.0 \pm 7.0(3) \ddagger$ & $44(3) \ddagger$ \\
HPRT $_{\text {Toronto }}$ & $4.6 \pm 2.1(4) \S$ & $14.5 \pm 7.7(3)$ & 28 \\
HPRT $_{\text {London }}$ & $20.2 \pm 4.3(12)$ & $10.2 \pm 5.0(6)$ & 74 \\
HPRT $_{\text {Ann Arbor }}$ & $33(31,34)^{\| \prime}$ & $38 \pm 13(6)$ & 41 \\
HPRT $_{\text {Munich }}$ & $261 \pm 53(4)$ & $5.9 \pm 2.4(3)$ & $2.6 \pi$ \\
HPRT $_{\text {Kinston }}$ & $555 \pm 107(3)$ & $2,025(2,100,1,950)$ & $50 \pi$ \\
D.B. $_{\text {D.G. }}$ & $20.2 \pm 3.2(4)$ & $11.9 \pm 4.0(3)$ & 58 \\
K.T. & $\mathrm{NM} *$ & $\mathrm{NM}$ & $\mathrm{NM}$ \\
& $\mathrm{NM}$ & $\mathrm{NM}$ & $\mathrm{NM}$ \\
\hline
\end{tabular}

* Defined as the maximum enzymatic activity divided by the total quantity of HPRT enzyme as measured by radioimmunoassay (see Methods).

$\ddagger$ Mean $\pm 1 \mathrm{SD} ;(n)=$ number of normal lines studied.

$\S$ Mean $\pm 1 \mathrm{SD} ;(n)=$ number of determinations.

"Average of two separate determinations. Individual values enclosed in parentheses.

I Extrapolated to maximum values from assays in which PRPP was saturating but hypoxanthine was not.

** NM, not measured because the enzyme variant had no detectable catalytic activity.
Differences in the net charge of HPRT variants were assessed by nondenaturing polyacrylamide gel electrophoresis. The known HPRT variants have been classified previously into three groups based on this electrophoretic parameter (11): normal migration, $\mathrm{HPRT}_{\text {London }}$ and $\mathrm{HPRT}_{\text {Ann Arbor }}$; cathodal migration, HPRT $_{\text {Kinston }}$ and HPRT Munich $_{\text {; and anodal migration, HPRT }}$ Toronto Membrane-free extracts of the previously uncharacterized patients, D.B., K.T., and D.G., were subjected to similar electrophoretic analysis, as shown in Fig. 1. Enzyme from D.B. was indistinguishable from normal HPRT (lane $N$ ), while HPRT from D.G. was more anodal than normal (but indistinguishable

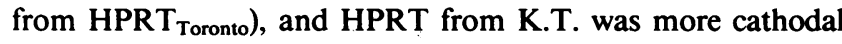
than normal (but similar to the other known cathodal variants HPRT $_{\text {Kinston }}$ and HPRT Munich $_{\text {). }}$

Differences in the apparent subunit molecular weight of the variant enzymes were identified by comparing their relative migration during SDS-polyacrylamide gel electrophoresis. Previous experiments demonstrated an essentially normal apparent subunit molecular weight for all of the known variants except HPRT $_{\text {London }}$, which exhibited a slightly lower apparent subunit molecular weight $(11,19)$. The protein blot technique was employed to quickly screen for marked alterations in apparent subunit molecular weight.

Membrane-free extracts from a normal cell line, the three previously uncharacterized enzyme-positive cell lines, and selected known HPRT variants, were electrophoresed in the presence of SDS, and the HPRT enzymes were detected immunochemically as described (Fig. 2). A single predominate molecular species with an apparent subunit molecular weight equal to 25,000 , as well as multiple additional nonpredominate bands, were detected in each cell line studied. Several observations indicate that the multiple nonpredominate bands are due to nonspecific binding of antibody, and that the 25,000-mol-wt species represents bonafide HPRT. All bands except the 25,000-mol-wt band are present when $(a)$ control serum is used in place of HPRT antiserum (data not shown), or (b) extracts from enzymedeficient cell lines lacking detectable HPRT immunoreactive

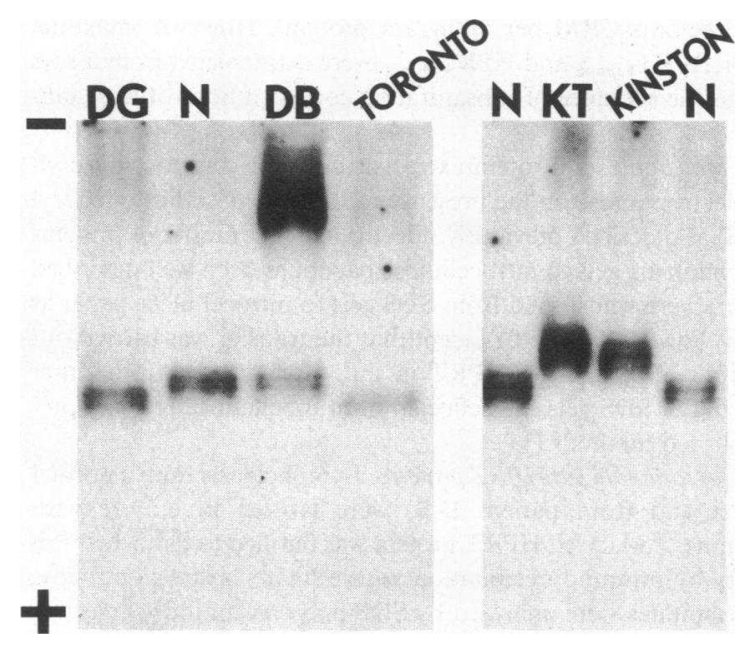

Figure 1. Protein blot analysis of lymphoblast HPRT after nondenaturing polyacrylamide gel electrophoresis. Lymphoblast extracts were electrophoresed in nondenaturing polyacrylamide gels and analyzed for HPRT immunoreactive protein as described in the Methods section. Similar quantities of cellular extract (500-250 $\mu \mathrm{g}$ protein) were electrophoresed in each lane. Lane $N$ represents extract from a lymphoblast cell line derived from a normal control. 


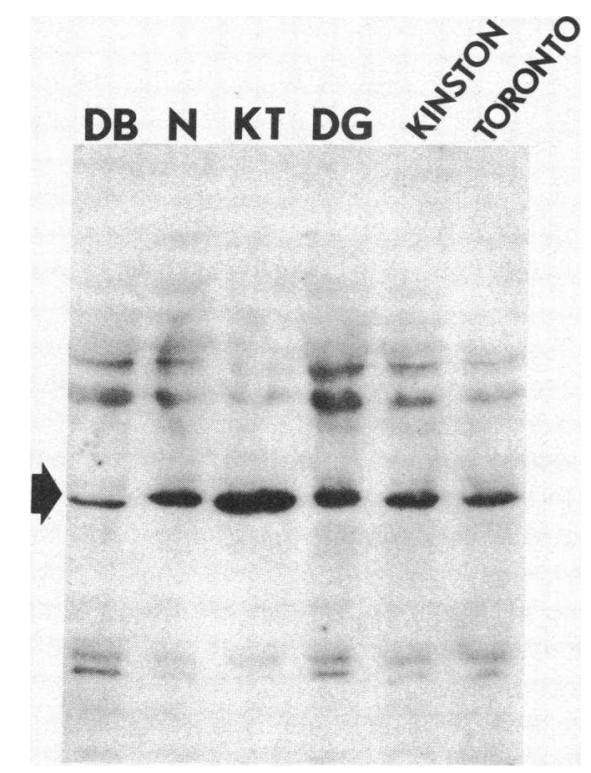

Figure 2. Protein blot analysis of lymphoblast HPRT after SDS-polyacrylamide gel electrophoresis. Lymphoblast extracts were electrophoresed under denaturing conditions in polyacrylamide gels containing SDS, and HPRT immunoreactive protein was detected in situ. Each lane contained similar quantities of cellular extract (500-250 $\mu \mathrm{g}$ total protein). Lane $N$ represents extract from a lymphoblast cell line derived from a normal control. The arrow indicates the location of HPRT.

protein were analyzed (data not shown). The apparent subunit molecular weight of HPRT from K.T. and D.G. is indistinguishable from normal HPRT (lane $N$ ). However, the migration of HPRT from D.B. appears to be slightly faster than normal HPRT and, therefore, the apparent subunit molecular weight somewhat lower.

We attempted to confirm the subtle decrease in apparent subunit molecular weight of HPRT from D.B. using an alternative method. HPRT from D.B. and from a normal lymphoblastoid cell line was labeled in culture with $\left[{ }^{35}\right.$ S]methionine and purified to homogeneity by immunoprecipitation. The radiochemically homogeneous enzymes were subjected to SDSpolyacrylamide gel electrophoresis and directly visualized by autoradiography (Fig. 3). The apparent subunit molecular weight of HPRT from D.B. was decreased as compared with the normal enzyme (lane $N$ ). This subtle difference in subunit molecular weight was better illustrated by demonstrating partial resolution of the normal and variant enzyme when co-electrophoresed (lane $N+$ D.B.).

Analysis of HPRT $m R N A$. Northern analysis revealed essentially normal concentrations of HPRT mRNA in 12 of 15

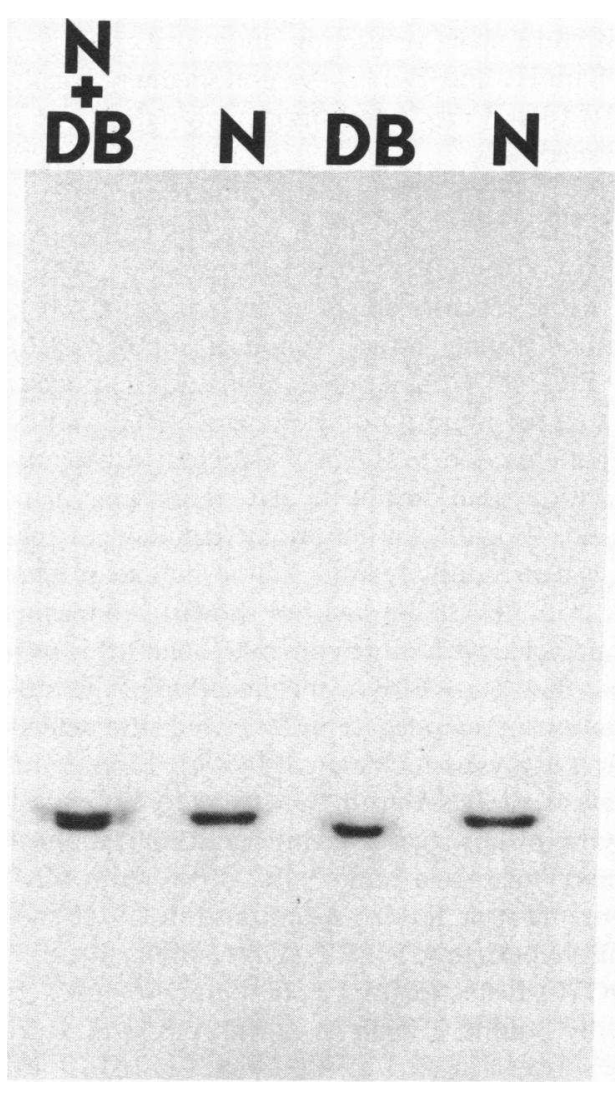

Figure 3. SDS-polyacrylamide gel electrophoresis of labeled lymphoblast HPRT. Lymphoblast HPRT labeled in culture with $\left[{ }^{35} S\right]$ methionine was denatured and subjected to SDS-polyacrylamide gel electrophoresis. Radiolabeled HPRT was identified by autoradiography. Lane $N$, purified enzyme from a normal lymphoblast cell line; lane $D B$, purified enzyme from D.B.; and lane $N+D B$, a mixture of purified enzyme from normal and D.B.

Lesch-Nyhan patients and 8 of 9 gouty patients (Fig. 4). Cell lines from McA (Lesch-Nyhan), W.E. (Lesch-Nyhan), GM2292 (Lesch-Nyhan), and B.D. (gout) had no detectable HPRT mRNA, even after longer autoradiographic exposures (Fig. 4). We estimate the sensitivity of this technique to be $>5 \%$ normal HPRT mRNA concentration.

GM6804 was the only cell line in which the HPRT mRNA exhibited altered electrophoretic properties; this abnormal mRNA migrated at an abnormally slow rate, consistent with an increase in molecular size from 1.6 to $1.8 \mathrm{~kb}$. Similar findings have been reported in fibroblasts derived from this patient (16).

Southern blot analysis of the HPRT gene. DNA from each cell line was examined by the method of Southern for alterations

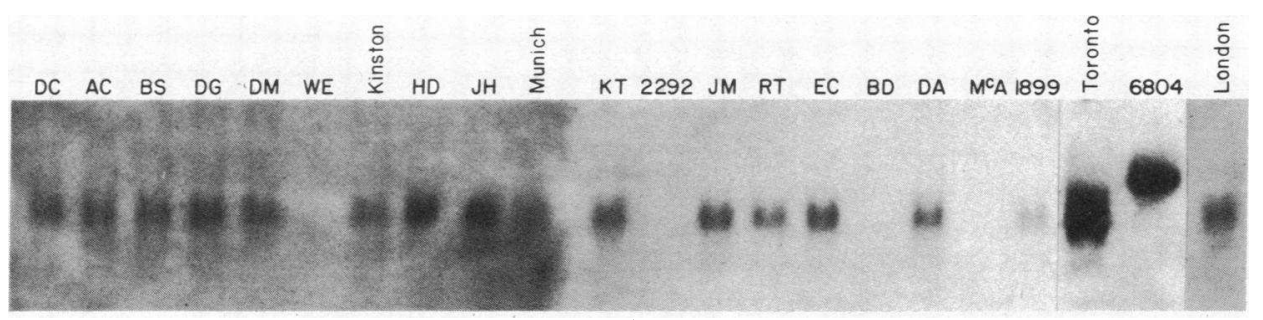

Figure 4. Northern blot analysis of lymphoblast HPRT mRNA. Total RNA ( $50 \mu \mathrm{g} /$ lane) was electrophoresed in agarose, transferred to nitrocellulose, and probed with ${ }^{32} \mathrm{P}$ labeled HPRT cDNA. Results from D.B., P.C., and HPRT Ann Arbor are not shown. 
in HPRT gene structure using restriction endonucleases. The presence of linked Bam $\mathrm{HI}$ and Taq I restriction fragment length polymorphisms (RFLPs) were determined with HPRT and DSX-10 probes, respectively.

The human HPRT gene is composed of nine exons distributed over $>40 \mathrm{~kb}$ of DNA $(8 ; 9$; T. Patel, personal communication). The integrity of the HPRT structural gene in mutant cell lines was assessed as recently described by Yang et al. (16); DNA was analyzed according to the method of Southern (26) using full-length HPRT cDNA as a probe. Using this approach, we demonstrated that the majority of these patients (13 out of 15 Lesch-Nyhan patients and 9 out of 9 patients with gouty arthritis) have mutations that do not involve major gene rearrangements (data not shown). An abnormal fragment, of low molecular weight, is consistently seen in Southern blots of Bam H1 digested DNA from GM1899 (data not shown). Abnormal fragments are not detected with other enzymes; hence, this represents either a rare Bam H1 RFLP or the detection of the mutation. Three mutations, previously reported, which are detectable by Southern analysis include GM6804, McA, and HPRT $_{\text {Toronto }}$. Analysis of DNA from GM6804 (lymphoblast culture from pt. GM1662) suggests an internal duplication of the HPRT gene involving exons 2 and 3 (16). DNA from McA (lymphoblast culture from pt. RJK853) demonstrates no X-specific fragments that hybridize to HPRT cDNA, indicative of a total gene deletion (16). Detection of the point mutation in exon 3 of HPRT Toronto by Southern analysis of DNA has been described (27).

Two HPRT-linked RFLPs have been described. Nussbaum reported a three-allele Bam H1 RFLP that occurs within the HPRT gene (28). These alleles are expressed phenotypically on Southern blots as three distinct pairs of fragments: a 22-kb, 25-kb pair; a 12-kb, 25-kb pair; and a 22-kb, 18-kb pair. An additional two-allele Taq I RFLP has been reported for an anonymous sequence (DXS-10) separate from, but closely linked to (95\% confidence limits $\theta<15 \mathrm{cM}$ ), the HPRT locus (29). These alleles are represented as 5 or $7 \mathrm{~kb}$ fragments on Southern anal- ysis. These RFLP patterns can be combined to establish six haplotypes, four of which are represented in this group of patients (Fig. 5). The most frequent haplotype (68\%) was that combining the 22-kb, 25-kb Bam $\mathrm{H} 1$ allele and the 5-kb Taq I allele (22, $25 / 5$ ). While $13 \%$ of all patients had the $22,25 / 7$ pattern, the $22,18 / 5$ and $12,25 / 5$ patterns were each seen in single patients. Therefore, $9 \%$ of patients have gene defects identifiable by Southern analysis.

\section{Discussion}

The inborn errors of metabolism are examples of disorders that are often caused by aberrations in the function or expression of single macromolecules. We have undertaken a comprehensive molecular analysis of a large population of patients with a deficiency of the enzyme HPRT, in an attempt to illustrate the spectrum and prevalence of genetic aberrations that underlie this prototype-inherited disease.

We studied 24 unrelated HPRT-deficient patients; 15 patients presented with the Lesch-Nyhan syndrome, while 9 patients presented with either gout or nephrolithiasis. A comprehensive analysis of the HPRT enzyme, mRNA, and gene provided the basis for the molecular classification summarized in Table III and Fig. 6.

Approximately $33 \%$ of all HPRT-deficient patients retained $>5 \%$ residual HPRT immunoreactive protein. These patients, referred to as the enzyme-positive $\left(\mathrm{CRM}^{+}\right)$group, provide many examples of an enzyme deficiency state caused by an abnormality in enzyme function. Five of these eight patients have been described previously, four of which have been shown to contain unique enzyme variants that differ from the normal enzyme by a single amino acid substitution. Patients D.B., D.G., and K.T. have not been described previously. HPRT enzymes from D.G. and K.T. exhibit unique constellations of electrophoretic and catalytic properties and therefore have been assigned the following names based on the geographical residence of the patients: HPRT $_{\text {New Haven }}$ (D.G.) and HPRT Yale $_{\text {(K.T.). In both cases, unique }}$
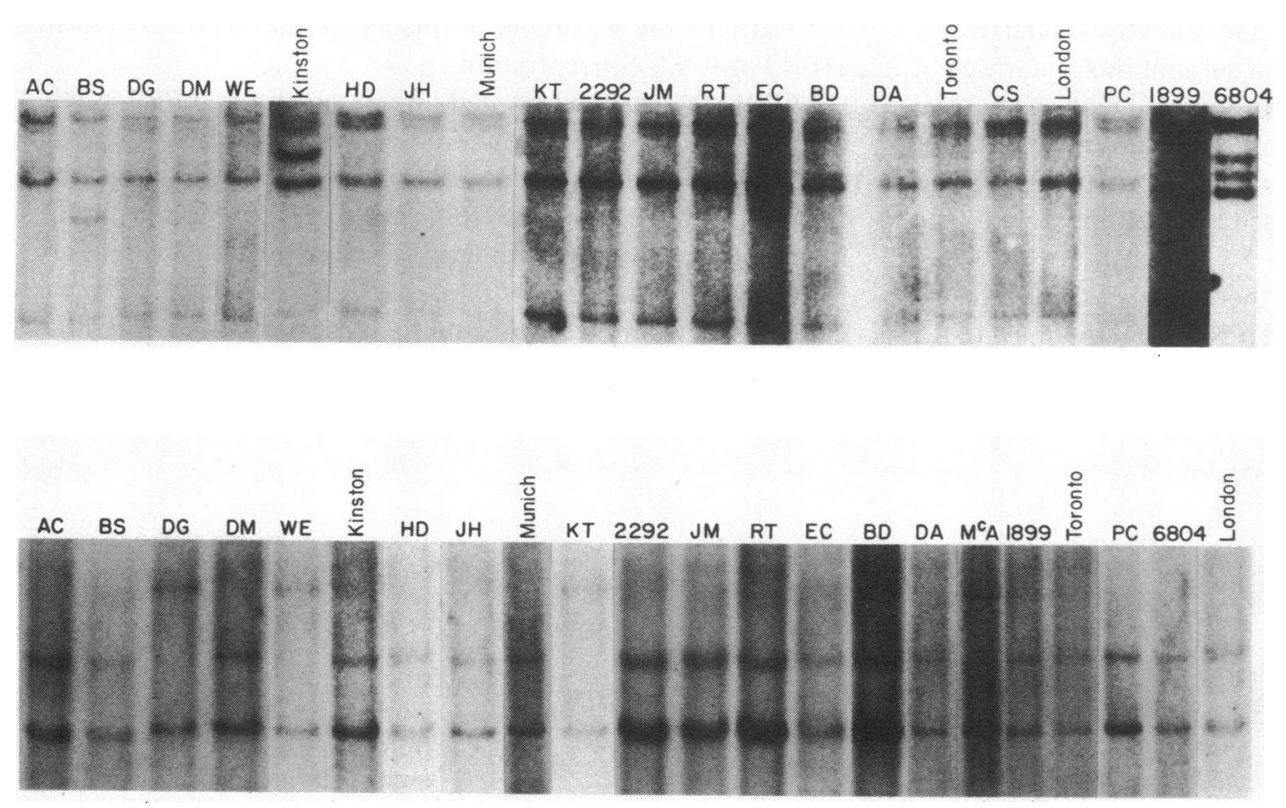

Figure 5. Southern blot analysis of selected lymphoblast HPRT DNA. (A) (top) DNA was digested to completion with Bam $\mathrm{H} 1$, electrophoresed through $0.8 \%$ agarose, transferred to nitrocellulose, and probed with full-length ${ }^{32} \mathrm{P}$-labeled HPRT cDNA. The portion of the autoradiograph demonstrating the polymorphisms is shown. (B) (bottom) DNA was digested to completion with Taq I, electrophoresed through $0.8 \%$ agarose, transferred to nitrocellulose, and probed with ${ }^{32}$ P-labeled DXS-1 DNA. 
Table III. Molecular Heterogeneity of HPRT Mutations

\begin{tabular}{|c|c|c|c|c|c|c|}
\hline \multirow[b]{2}{*}{ Patients } & \multicolumn{3}{|c|}{ Protein analysis } & \multicolumn{2}{|c|}{ Nucleic acid analysis } & \multirow[b]{2}{*}{ Type } \\
\hline & CRM & Kinetic properties & $\begin{array}{l}\text { Electrophoretic } \\
\text { properties }\end{array}$ & mRNA & DNA haplotype* & \\
\hline & $\%$ control & & & & $k b$ & \\
\hline \multicolumn{7}{|l|}{ Lesch-Nyhan } \\
\hline \multicolumn{7}{|l|}{ D.A., A.C., E.C., } \\
\hline H.D., J.H., D.M. & $<0.6$ & NM & ND§ & + & $22,25 / 5$ & I \\
\hline B.S. & $<0.6$ & NM & ND & + & $12,25 / 5$ & II \\
\hline GM1899 & 1.3 & NM & ND & + & $22,25 / 5^{\prime \prime}$ & III \\
\hline GM6804 & $<0.6$ & NM & ND & Variant $\pi$ & Duplication $/ 5^{* *}$ & IV \\
\hline McA & $<0.6$ & NM & ND & - & Deletion/7ł & V \\
\hline W.E. & $<0.6$ & NM & ND & - & $22,25 / 7$ & VI \\
\hline GM2292 & $<0.6$ & NM & ND & - & $22,25 / 5$ & VII \\
\hline K.T. (HPRT Yale $)$ & 92 & NM & Cathodal & + & $22,25 / 7$ & VIII \\
\hline $\mathrm{HPRT}_{\text {Kinston }}$ & 72 & $\uparrow K_{\mathrm{m}} \mathrm{Hx}$ and PRPP & Cathodal & + & $22,18 / 5$ & IX \\
\hline D.G. $\left(\mathrm{HPRT}_{\text {New Haven }}\right)$ & 50 & NM & Anodal & + & $22,25 / 7$ & $\mathrm{X}$ \\
\hline \multicolumn{7}{|l|}{ Gout } \\
\hline P.C., R.T., J.M. & $4-0.8$ & NM & ND & + & $22,25 / 5$ & $\mathrm{XI}$ \\
\hline B.D. & 2 & NM & ND & - & $22,25 / 5$ & XII \\
\hline HPRT $_{\text {Ann Arbor }}$ & 11 & $\uparrow K_{\mathrm{m}} \mathrm{Hx}$ and PRPP & Neutral & + & $22,25 / 5$ & XIII \\
\hline HPRT $_{\text {Toronto }}$ & 52 & Normal & Anodal & + & $22,25 / 5$ & XIV \\
\hline HPRT $_{\text {Munich }}$ & 79 & $\uparrow K_{\mathrm{m}} \mathrm{Hx}$ and $\downarrow V_{\max }$ & Cathodal & + & $22,25 / 5$ & $\mathrm{XV}$ \\
\hline HPRT $_{\text {London }}$ and D.B. & $35-52$ & $\uparrow K_{\mathrm{m}} \mathrm{Hx}$ & $\begin{array}{l}\text { Neutral and } \\
\text { lapparent size }\end{array}$ & + & $22,25 / 5$ & XVI \\
\hline
\end{tabular}

* DNA haplotype: Bam H1 polymorphisms/DXS-10 polymorphisms. $¥ N M$, not measured because of limited catalytic activity of the residual enzyme. $\S$ Not determined due to limited residual enzyme protein. "A rare Bam H1 polymorphism linked to the HPRT gene results in the production of low molecular weight restriction fragment. I This mRNA is slightly larger than normal. ** Internal duplication of exons 2 and 3. 拉 The entire structural gene has been deleted.

structural gene mutations have rendered the enzymes completely incompetent and have resulted, clinically, in the Lesch-Nyhan syndrome. HPRT from D.B. appears identical to HPRT London in terms of its electrophoretic and catalytic properties, despite the fact that patients D.B. and G.S. share no apparent common heritage. Molecular studies are needed to determine if D.B. has the identical missence mutation of HPRT $_{\text {London }}(\operatorname{Ser} 109 \rightarrow$ Leu).

The majority of HPRT-deficient patients demonstrate no

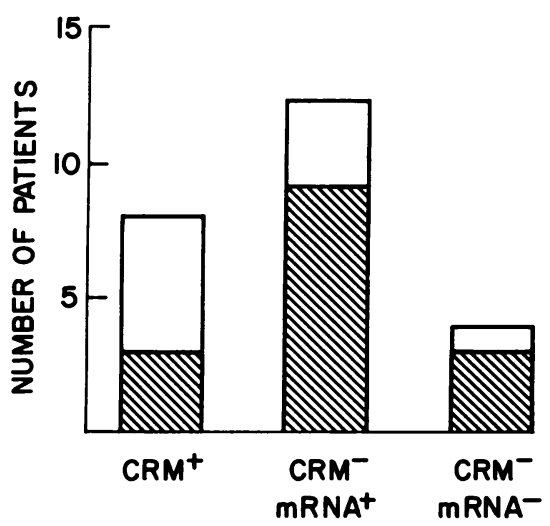

Figure 6. Molecular classification of HPRT-deficient patients. 口, gout; ๑, Lesch-Nyhan. detectable HPRT protein. Quantification of HPRT mRNA further subdivided this large group of patients into those with HPRT mRNA (CRM ${ }^{-} \mathrm{mRNA}^{+}$) and those without detectable HPRT mRNA ( $\mathrm{CRM}^{-} \mathrm{mRNA}^{-}$). The former group, comprising $50 \%$ of all patients, represents those for which the genetic lesion has affected either the function of mRNA (i.e., efficiency of translation) or the stability of the translation product. Mutations that have a selective effect on the efficiency of mRNA translation without affecting the stability of either the mRNA or its translation product are, to the best of our knowledge, without precedent in mammalian systems. The alternative and more likely explanation is that the native enzyme is relatively intolerant to slight perturbations so that minor structural changes, such as amino acid substitutions, may frequently affect enzyme stability and thereby lead to an accelerated intracellular degradation of enzyme protein. A first step in understanding the molecular pathology of this large group of patients is to define the specific mutations involved.

The final category of patients, comprising only $17 \%$ of all patients studied, includes those with undetectable HPRT protein and mRNA (CRM ${ }^{-} \mathrm{mRNA}^{-}$). This molecular form of HPRT deficiency is analogous to the thalassemia syndromes, which are a heterogeneous collection of genetic diseases that result from defects in the organization and/or expression of globin genes. In a previous study, Yang et al. demonstrated deletion of major sections of the HPRT structural gene in three of four patients 
who were void of detectable HPRT mRNA (16). ${ }^{3}$ Identical analyses failed to identify abnormalities in the HPRT gene of the three new $\mathrm{CRM}^{-} \mathrm{mRNA}^{-}$patients described in this study. However, small deletions or insertions may have inperceptible changes in restriction fragment mobility and therefore may be missed when analyzed according to the method of Southern.

The molecular and clinical characterization of 24 unrelated HPRT-deficient patients summarized above provides direct evidence for the existence of 12 unique mutations at the HPRT locus. Indirect evidence for even greater genetic heterogeneity in this population was provided through the study of linked RFLPs. Neutral haplotype analysis permits the identification of genetic backgrounds on which HPRT mutational events occurred, thus expanding the number of documented independent mutations. Several HPRT-deficient patients who were previously indistinguishable now become identifiable as unique mutational events. Characterization of the clinical biochemical and molecular properties of the 24 unrelated HPRT-deficient patients, in concert with haplotype analysis, provides indirect evidence for the existence of 16 unique aberrant genes in this population. Pertinent data that define these unique mutations are summarized in Table III. This marked molecular heterogeneity provides further support for the concept originally proposed by Haldane, that $\mathrm{X}$-linked recessive disorders are sustained in the population by the constant introduction of new mutations. Furthermore, the present study demonstrates that each category of mutation, as outlined in Fig. 6, is represented in both clinical syndromes. However, mutations with less deleterious effects on enzyme function in vivo (e.g., most amino acid substitutions that affect enzyme function but not enzyme concentration) are more often associated with patients who are spared the devastating neurologic and behavioral abnormalities of Lesch-Nyhan syndrome.

In conclusion, we analyzed a large population of unrelated HPRT-deficient patients with respect to abnormalities in the HPRT enzyme, mRNA, and gene. This study provides insight into the spectrum and prevalence of mutations that underlie this heterogeneous disorder and illustrates the kind of mutations that can lead to inherited disease in man.

\section{Acknowledgments}

We would like to thank L. Landa and K. Holmes for their excellent research assistance.

This work was supported by grants AM-19045 and AM-31428 from the National Institutes of Health and also by the Howard Hughes Foundation. Mr. Stout was supported by the Philip M. Berlozheimer Fellowship. Dr. Wilson was supported by the Medical Scientist Training Program at the University of Michigan.

\section{References}

1. Seegmiller, J. E., F. M. Rosenbloom, and W. N. Kelley. 1967. Enzyme defect associated with a sex-linked human neurological disorder and excessive purine synthesis. Science (Wash. DC). 155:1682-1684.

2. Lesch, M., and W. L. Nyhan. 1964. A familial disorder of uric acid metabolism and central nervous system function. Am. J. Med. 36: 561-570.

3. Kelley, W. N., F. M. Rosenbloom, J. F. Henderson, and J. E.

3. One of four $\mathrm{CRM}^{-} \mathrm{mRNA}^{-}$patients presented in this study was also characterized by Yang et al. (16); lymphoblast cell line McA corresponds to fibroblast cell line RJK853.
Seegmiller. 1967. A specific enzyme defect in gout associated with overproduction of uric acid. Proc. Natl. Acad. Sci. USA. 57:1735-1739.

4. Wilson, J. M., G. E. Tarr, W. C. Mahoney, and W. N. Kelley. 1982. Human hypoxanthine-guanine phosphoribosyltransferase: complete amino acid sequence of the erythrocyte enzyme. J. Biol. Chem. 257:10978-10985.

5. Argos, P., M. Hanei, J. M. Wilson, and W. N. Kelley. 1983. A possible nucleotide-binding domain in the tertiary fold of phosphoribosyltransferases. J. Biol. Chem. 258:6450-6457.

6. Konecki, D. S., J. Brennand, J. C. Fuscoe, C. T. Caskey, and A. C. Chinault. 1982. Hypoxanthine-guanine phosphoribosyltransferase genes of mouse and Chinese hamster: construction and sequence analysis of cDNA recombinants. Nucleic Acids Res. 10:6763-6775.

7. Jolly, D. J., H. Okayama, P. Berg, A. C. Esty, D. Filpula, P. Bohlen, G. G. Johnson, J. E. Shively, T. Hunkapiller, and T. Friedmann. 1982. Isolation and characterization of a full-length expressible cDNA for human hypoxanthine-guanine phosphoribosyltransferase. Proc. Natl. Acad. Sci. USA. 80:477-481.

8. Melton, D. W., D. S. Konecki, J. Brennand, and C. T. Caskey. 1984. Structure, expression and mutation of the hypoxanthine phosphoribosyltransferase gene. Proc. Natl. Acad. Sci. USA. 81:2147-2151.

9. Patel, P. I., R. L. Nussbaum, P. E. Framson, D. H. Ledbetter, C. T. Caskey, and A. C. Chinault. 1984. Organization of the HPRT gene and related sequences in the human genome. Somatic Cell Mol. Genet. 10:483-493.

10. Kelley, W. N., M. L. Greene, F. M. Rosenbloom, J. F. Henderson, and J. E. Seegmiller. 1969. Hypoxanthine-guanine phosphoribosyltransferase deficiency in gout. Ann. Intern. Med. 70:155-206.

11. Wilson, J. M., B. W. Baugher, P. M. Mattes, P. E. Daddona, and W. N. Kelley. 1982. Human hypoxanthine-guanine phosphoribosyltransferase. Demonstration of structural variants in lymphoblastoid cells derived from patients with a deficiency of the enzyme. J. Clin. Invest. 69:706-715.

12. Wilson, J. M., G. E. Tarr, and W. N. Kelley. 1983. Human hypoxanthine-guanine phosphoribosyltransferase: an amino acid substitution in a mutant form of the enzyme isolated from a patient with gout. Proc. Natl. Acad. Sci. USA. 80:870-873.

13. Wilson, J. M., R. Kobayashi, I. H. Fox, and W. N. Kelley. 1983. Human hypoxanthine-guanine phosphoribosyltransferase: molecular abnormality in a mutant form of the enzyme (HPRT Toronto $)$ J. Biol. Chem. 258:6458-6460.

14. Wilson, J. M., and W. N. Kelley. 1984. Human hypoxanthineguanine phosphoribosyltransferase: structural alteration in a dysfunctional enzyme variant (HPRT Munich ) isolated from a patient with gout. J. Biol. Chem. 259:27-30.

15. Wilson, J. M., and W. N. Kelley. 1983. Molecular basis of hypoxanthine-guanine phosphoribosyltransferase deficiency in a patient with the Lesch-Nyhan syndrome. J. Clin. Invest. 71:1331-1335.

16. Yang, T. P., P. I. Patel, A. C. Chinault, J. T. Stout, L. G. Jackson, B. H. Hildebrand, and C. T. Caskey. 1984. Molecular evidence for new mutation at the HPRT locus in Lesch-Nyhan patients. Nature (Lond.). 310:412-414.

17. Kelley, W. N., and J. B. Wyngaarden. 1983. Clinical syndromes associated with hypoxanthine-guanine phosphoribosyltransferase deficiency. In The Metabolic Basis of Inherited Disease. J. B. Stanbury, J. B. Wyngaarden, D. S. Fredrickson, J. L. Goldstein, and M. S. Brown, editors. McGraw-Hill, New York. 5th ed. 1115-1143.

18. Holden, J. A., and W. N. Kelley. 1978. Human hypoxanthineguanine phosphoribosyltransferase: evidence for a tetrameric structure. J. Biol. Chem. 253:4459-4463.

19. Wilson, J. M., B. W. Baugher, L. Landa, and W. N. Kelley. 1981. Human hypoxanthine-guanine phosphoribosyltransferase: purification and characterization of mutant forms of the enzyme. J. Biol Chem. 256: 10306-10312.

20. Towbin, H., T. Staehelin, and J. Gordon. 1979. Electrophoretic transfer of proteins from polyacrylamide gels to nitrocellulose sheets: procedure and some applications. Proc. Natl. Acad. Sci. USA. 76:43504354. 
21. Fuscoe, J. C., R. G. Fenwick, Jr., D. H. Ledbetter, and C. T. Caskey. 1983. Deletion and amplification of the HGPRT locus in Chinese hamster cells. Mol. Cell. Biol. 3:1086-1096.

22. McDonald, J. A., and W. N. Kelley. 1971. Lesch-Nyhan syndrome: altered kinetic properties of mutant enzyme. Science (Wash. DC). 171:689-691.

23. Grober, W., and N. Zollner. 1979. Properties of hypoxanthineguanine phosphoribosyltransferase (HGPRTase) in a gout patient with partial deficiency of this enzyme. Klin. Wochenschr. 57:63-68.

24. Fox, I. H., I. L. Dwosh, P. J. Marchant, S. Lacroix, M. R. Moore, S. Omura, and V. Wyhofsky. 1975. Hypoxanthine-guanine phosphoribosyltransferase. Characterization of a mutant in a patient with gout. $J$. Clin. Invest. 56:1239-1249.

25. Sweetman, L., M. Borden, P. Lesh, B. Bakay, and M. A. Becker. 1977. Diminished affinity for purine substrates as a basis for gout with mild deficiency of hypoxanthine-guanine phosphoribosyltransferase. In
Purine Metabolism in Man II: Regulation of Pathways and Enzyme Defects. M. M. Muller, E. Kaiser, and J. E. Seegmiller, eds. Plenum Press, New York. 319-325.

26. Southern, E. M. 1975. Detection of specific sequences among DNA fragments separated by gel electrophoresis. J. Mol. Biol. 98:503-517.

27. Wilson, J. M., P. Frossard, R. L. Nussbaum, C. T. Caskey, and W. N. Kelley. 1983. Human hypoxanthine-guanine phosphoribosyltransferase. Detection of a mutant allele by restriction endonuclease analysis. J. Clin. Invest. 72:767-772.

28. Nussbaum, R. L., W. E. Crowder, W. L. Nyhan, and C. T. Caskey. 1983. A three-allele restriction fragment length polymorphism at the hypoxanthine phosphoribosyltransferase locus in man. Proc. Natl. Acad. Sci. USA. 80:4035-4039.

29. Boggs, B. A., and R. L. Nussbaum. 1984. Two anonymous X-specific human sequences detecting restriction fragment length polymorphisms in region Xq26 $\rightarrow$ qter. Somatic Cell Mol. Genet. 10:607-613. 